\title{
Sistem Informasi Pendaftaran Mahasiswa Baru Menggunakan Framework Codeigniter dan Application Programming Interface
}

\author{
Harlen Gilbert Simanullang ${ }^{1}$, Arina Prima Silalahi ${ }^{2}$, Darwis Robinson Manalu ${ }^{3}$ \\ ${ }^{1,2,3}$ Universitas Methodist Indonesia, Fakultas Ilmu Komputer, Medan, Indonesia \\ ${ }^{1}$ harlen.gilbert@gmail.com, ${ }^{2}$ primaarinasilalahi@gmail.com, ${ }^{3}$ manaludarwis@ gmail.com \\ Diterima 03 November 2020 \\ Disetujui 21 Juni 2021
}

\begin{abstract}
One of the most important things in the work process is the presentation of information that is fast and accurate. Data is processed in a short time, it will increase work efficiency, one of which is by using the system to process and display data into information. Information systems are needed considering technology is growing and now people are required to use more technology to reduce activities outside the home. Problems that often arise are the tight location of registration and the length of service for one registrant due to filling out registration forms and screening examinations for new students. In addition, the large accumulation of registration and trial files also takes a long time so that announcements of new student graduations cannot be made. The goal is to build a new student admission information system for all faculties at the Indonesian Methodist University, reduce applicants who come to the registration location, reduce the use of paper registration forms, help submit and fill in student data, conduct online screening exams, provide information on new student registration, schedule and payment of tuition fees. The result of this initialization is building a new student registration information system using the Codeigniter Framework and Application Programming Interface (API).
\end{abstract}

Index Terms-Application Programming Interface (API); Codeigniter framework; information systems; online registration

\section{PENDAhUluan}

Pendidikan merupakan hal penting untuk mendapatkan wawasan dan ilmu guna meningkatkan kemampuan sumber daya manusia yang cerdas, kreatif dan bermartabat[1]. Sumber daya manusia yang unggul dan berkualitas berperan untuk membangun negara, sehingga banyak orang berjuang untuk memperoleh pendidikan tinggi dan kementerian bersedia memberikan biaya tambahan/beasiswa bagi calon mahasiswa yang kurang mampu[2]. Namun yang menjadi kendala adalah bagaimana untuk melakukan pendaftaran mahasiswa secara daring/online mengingat kebutuhan pemahaman teknologi harus meningkat seiring berkembangnya teknologi. Masyarakat saat ini dituntut untuk memahami teknologi baik dalam kondisi apapun sehingga Institusi juga harus menyikapi persoalan teknologi untuk mendukung kinerja sumber daya manusia dalam ketersediaan informasi pendaftaran mahasiswa baru[3].

Pendaftaran mahasiswa dengan mengandalkan cara lama yaitu mendaftar di lokasi yang disediakan merupakan salah satu kendala mengingat pendataan calon mahasiswa yang membutuhkan waktu lama, merekap data dari seluruh pendaftar membutuhkan waktu yang lama, membuat pelaporan terkendala karena harus melakukan proses rekap data yang cukup lama, melakukan ujian penyaringan calon mahasiswa baru yang membutuhkan ruangan dan fasilitas lain yang memadai, keterbatasan ruangan pendaftaran, belum dapat memberikan informasi aktual mengenai kelulusan test dan pembayaran biaya kuliah.

Dalam kondisi apapun terlebih kondisi pandemi Covid-19, cara pendaftaran tersebut tidak efektif untuk membantu pengelolaan data pendaftar sehingga dibutuhkan sebuah sistem yang mampu membantu panitia dalam mengelola semua aktivitas pendaftaran.

Tujuan dari penelitian ini adalah membahas mengenai perlunya sebuah sistem yang dirancang untuk memberikan layanan terbaik bagi calon mahasiswa, dan mengatasi permasalahan pendaftaran manual di lokasi pendaftaran. Sehingga memberi manfaat yang signifikan untuk meningkatkan pendaftar baru, memberikan informasi yang aktual bagi pendaftar dan sebagai media promosi.

Berdasarkan permasalahan tersebut diperlukan sebuah Sistem Informasi Pendaftaran Mahasiswa Baru menggunakan Framework Codeigniter dan Application Programming Interface. Framework Codeigniter digunakan untuk mempermudah pembangunan sistem berbasis web, membuat tampilan website lebih menarik dan lebih dinamis apabila dibuka dengan perangkat apapun. Application Programming Interface yang akan digunakan adalah Application Programming Interface dari aplikasi 
Whatsapp sebagai pemberitahuan mengenai tahap/alur pendaftaran kepada calon mahasiswa.

\section{TINJAUAN PUSTAKA}

\section{A. Sistem}

Sistem secara umum berfungsi untuk mengolah data menjadi informasi yang berharga dan dapat digunakan membantu proses hingga mencapai tujuan. Sistem dibangun untuk mendukung pencapaian kesuksesan seperti pengolahan dan manajemen data/informasi agar tercapai sesuai dengan target yang diinginkan[4]. Sistem terdiri dari kumpulan proses ataupun procedural kerja yang saling berkaitan untuk bersama menyelesaikan tujuan dari pengadaan sistem tersebut[5]. Sistem dirancang oleh programmer sedemikian rupa dengan menentukan prosedurprosedur yang saling terkait, membentuk sebuah konsep yang terarah agar menghasilkan suatu tujuan dan membantu pekerjaan mulai dari mengumpulkan data, memasukkan, menyimpan, mengelola itu dalam pengolahan data ataupun mempresentasikan data.

\section{B. Sistem Informasi}

Sistem informasi diartikan sebagai sistem yang sering digunakan untuk melakukan komunikasi data antara antara manusia, proses, algoritmik, data dan teknologi[6]. Dengan adanya sistem, pekerjaan manajemen data akan lebih mudah dilakukan daripada menggunakan cara manual seperti mencatat dan melaporkan hasil di kertas. Sistem yang diharapkan mampu mengatasi masalah pengelolaan data sehingga alur kerja dapat diselesaikan dengan tepat dalam waktu yang singkat, hasil yang akurat dan informasi mengenai alur pendaftaran dapat diperoleh calon mahasiswa dengan aktual.

Sistem informasi yang akan dikembangkan terhubung dengan adanya database sebagai penyimpan data. Data yang disimpan mungkin banyak dan dapat diakses kapan saja[7].

\section{Framework Codeigniter}

Framework Codeigniter digunakan untuk mempermudah pembangunan sistem berbasis web, membuat tampilan website lebih menarik dan lebih dinamis apabila dibuka dengan perangkat apapun[8]. Framework Codeigniter atau yang biasa disebut CI berisi library fungsi dan class dengan kegunaan yang berbeda-beda, siap panggil dan dapat digunakan secara kondisional dengan tujuan mempermudah perancangan dapat mempermudah dan mempercepat pekerjaan Programmer [9], [10].

Framework Codeigniter juga dapat memanggil semua library yang sudah tersedia, hal tersebut mempermudah programmer merancang sistem dengan cepat karena menyediakan struktur yang mudah untuk dipanggil, dapat diatur dengan baik dan kondisional[8], [10], [11].
Keuntungan mengunakan Codeigniter[12], diantaranya sebagai berikut:

1. Tidak dikenakan biaya apapun karena bersifat opensource.

2. Codeigniter dapat diproses di PHP5.

3. File Codeigniter berukuran lebih kecil dari framework lain.

4. Menggunakan konsep MVC.

5. Link URL yang sederhana.

6. Paket library yang lengkap sehingga mempermudah perancang membuat website yang interaktif dan menarik.

Sistem dapat dikembangkan dengan mudah menggunakan plugin dan helper, atau dengan menggunakan hooks.

7. Tidak memerlukan template engine.

8. Codeigniter memiliki dokumentasi lebih lengkap dan jelas.

D. Application Programming Interface (API)

Application Programming Interface terdiri dari kumpulan perintah untuk merancang perangkat lunak yang berperan sebagai komunikator antara program berkomunikasi, API menerima permintaan pengguna lalu mengarahkan ke sistem agar sistem merespon permintaan tersebut[13], [14]. API digunakan agar lebih dari satu bagian prosedur/program dapat saling berinteraksi[15], [16]. API yang akan digunakan adalah API dari aplikasi Whatsapp sebagai pemberitahuan mengenai tahap/alur pendaftaran kepada calon mahasiswa. Pemberitahuan menggunakan API WhatsApp diperlukan mengingat saat ini banyak masyarakat Indonesia menggunakan WhatsApp sebagi salah satu media sosial untuk bersosialisasi dan sebagai penyampaian pesan teks maupun suara baik antara individu dan kelompok[17].

\section{Metodologi}

Metodologi penelitian yang dilakukan untuk pengembangan sistem ini adalah dengan menggunakan model Waterfall yaitu melakukan tahap demi tahap secara berurutan[18]. Tahap model Waterfall dapat dilihat pada Gambar 1. 


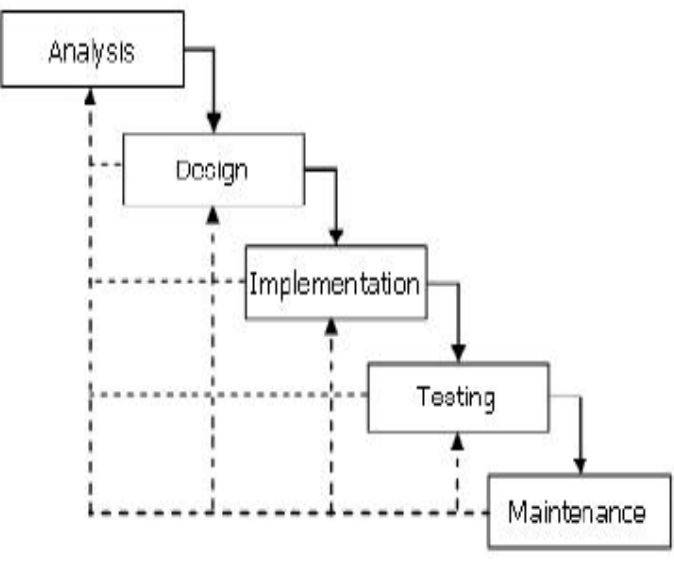

Gambar 1. Tahapan Waterfall

\section{Analysis (Analisis)}

Tahap analisis diperlukan untuk melihat permasalahan yang sedang terjadi dan mencari kemungkinan solusi yang bisa diberikan serta kebutuhan sistem ataupun pengguna. Analisis sistem dilakukan untuk mengetahui sifat dan kebutuhan program yang akan dibangun, memahami domain informasi, tingkah laku, unjuk kerja, dan antarmuka yang diperlukan[19]. Dari permasalahan diatas, dapat dilihat bahwa diperlukan sebuah sistem untuk membantu proses pendaftaran, proses Testing mahasiswa baru, proses pelaporan/rekap data dan memberikan informasi aktual mengenai alur pendaftaran ataupun hasil ujian.

\section{Design (Desain)}

Tahap desain dilakukan setelah Analisa selesai dilakukan. Desain sistem dapat berupa prototype untuk menampilkan gambaran dasar dari sistem yang akan dibangun.

\section{Implementation (Implementasi)}

Tahap implementasi dilakukan untuk merancang desain yang sudah diselesaikan. Pada tahap ini programmer mengimplementasikan desain dan analisis yang sudah dirancang sebelumnya.

\section{Testing (Pengujian)}

Pada tahap testing biasanya adalah tahap yang menentukan tercapai atau tidaknya tujuan sebuah sistem. Tahap testing juga dilakukan untuk melihat kesalahan dan perbaikan sistem.

\section{Maintenance (Pemeliharaan)}

Tahap ini dilakukan sebagai pemeliharaan sistem agar tetap berjalan dengan baik ataupun meningkatkan sistem.

\section{HASIL DAN PEMBAHASAN}

Analisa masalah dapat dikatakan sebagai suatu proses untuk menemukan masalah. Pengelolaan data dan layanan pendaftaran mahasiswa baru butuh perbaikan sehingga dibutuhkan sebuah sistem yang mampu membantu panitia dalam mengelola semua aktivitas pendaftaran yaitu Sistem Informasi Pendaftaran Mahasiswa Baru menggunakan Framework Codeigniter dan Application Programming Interface (API).

Sistem ini dirancang dua sisi yaitu sisi Panitia penerimaan mahasiswa baru dan sisi pendaftar. Sistem di sisi panitia diberikan fitur seperti:

1. Kelola data program studi, data petugas persyaratan pendaftaran, data soal TPA.

2. Fitur upload bukti pembayaran pendaftaran/pembayaran biaya kuliah.

3. Fitur impor data pendaftar yang mendaftar di lokasi atau offline.

4. Fitur laporan ujian TPA, nilai, daftar yang lulus tes dan remedial tes.

5. Fitur laporan pendaftar tiap program studi, laporan pembayaran biaya pendaftaran atau biaya kuliah.

Sistem di sisi pendaftar disediakan fitur antara lain:

1. Informasi persyaratan pendaftar, biaya pendaftaran dan jadwal seleksi.

2. Registrasi dan alur pendaftaran serta pembayaran.

3. Seleksi online.

4. Fitur profil kampus dan kontak person.

5. Fitur upload bukti bayar biaya pendaftaran dan biaya kuliah.

Alur sistem ini berawal dari petugas menginput informasi yang akan disajikan ke pendaftar berupa syarat pendaftaran, biaya, jadwal mulai perkuliahan, program studi. Kemudian pendaftar mengisi form registrasi dan upload semua berkas-berkas yang diperlukan untuk mendaftar sebagai mahasiswa sesuai dengan persyaratan yang sudah diinput petugas ke sistem.

Sistem yang dibangun memanfaatkan Application Programming Interface (API) yang akan digunakan sebagai notifikasi untuk menuntun pendaftar melanjutkan ke tahap berikutnya. Setelah selesai registrasi dan upload berkas pendafaran, webserver akan mengirimkan pesan, API Key beserta API Password ke server onyxberry Whatsapp API sebagai penyedia API Whatsapp. Pesan akan diteruskan ke server Whatsapp kemudian ke Whatsapp pengguna. API yang digunakan adalah satu arah, artinya tidak 
dapat melakukan pertukaran informasi karena hanya dgunakan sebagai pemberitahuan tahapan pendaftaran hingga upload bukti pembayaran uang kuliah. Tahapan terakhir bagi pendaftar adalah mengikuti seleksi online setelah pendaftar membayar uang kuliah. Apabila seleksi dinyatakan lulus, maka surat kelulusan akan dapat langsung dicetak melalui sistem.

Use Case Sistem Informasi Pendaftaran Mahasiswa Baru dapat dilihat pada Gambar 2.

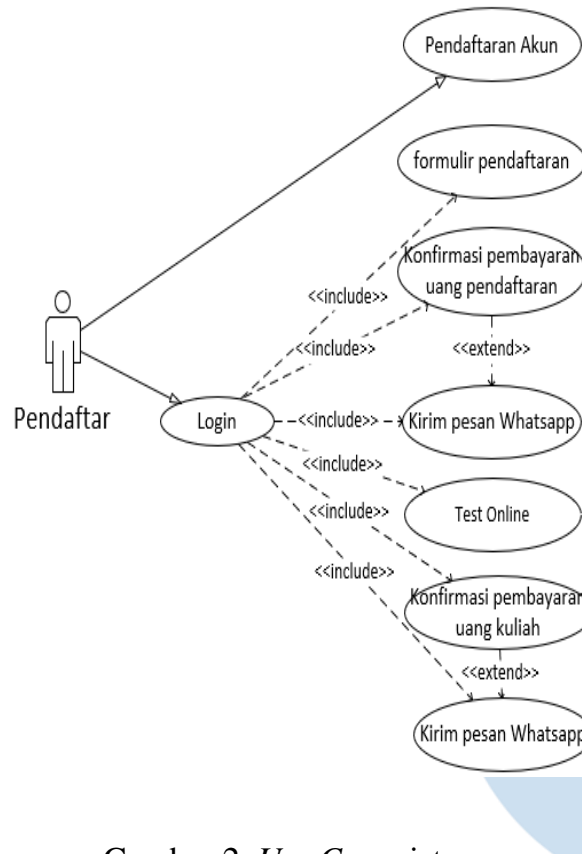

Gambar 2. Use Case sistem

Use Case admin dalam pengelolaan sistem dapat dilihat pada Gambar 3.

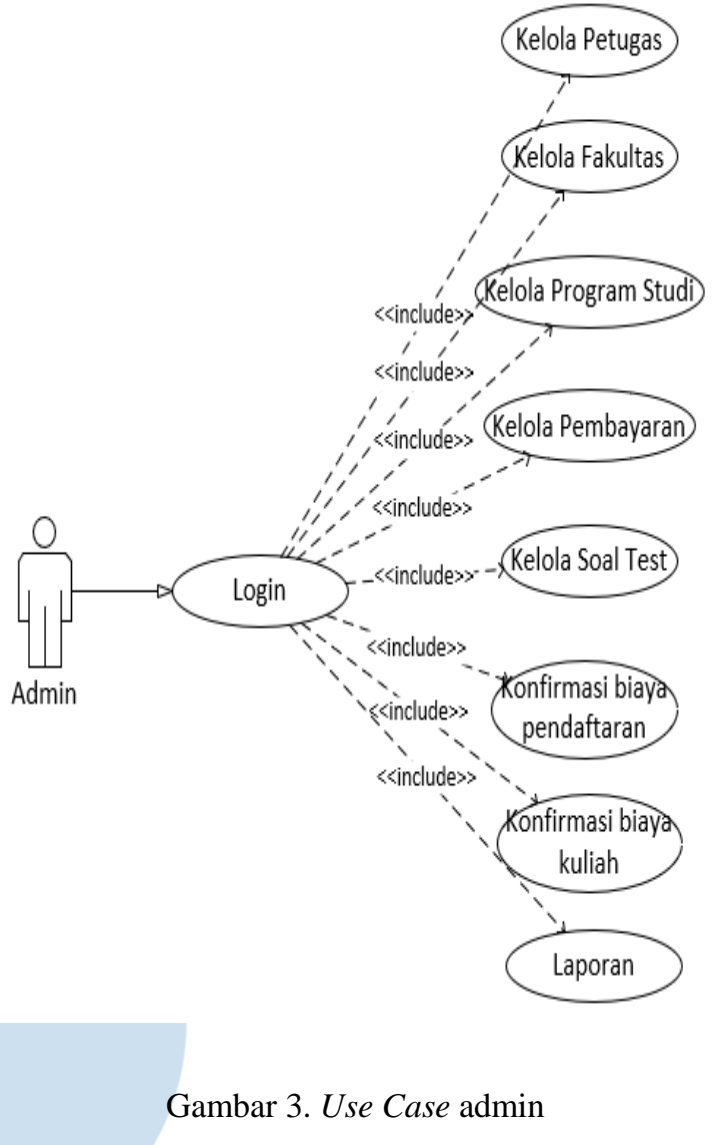

Pendaftar akan menerima pemberitahuan mengenai konfirmasi uang pembayaran, dan uang kuliah yang bukti pembayarannya sudah dicek oleh admin. Pemberitahuan akan dikirim melalui API Whatsapp satu alur. Alur kerja API Whatsapp dalam sistem informasi pendaftaran mahasiswa baru pada Gambar 4

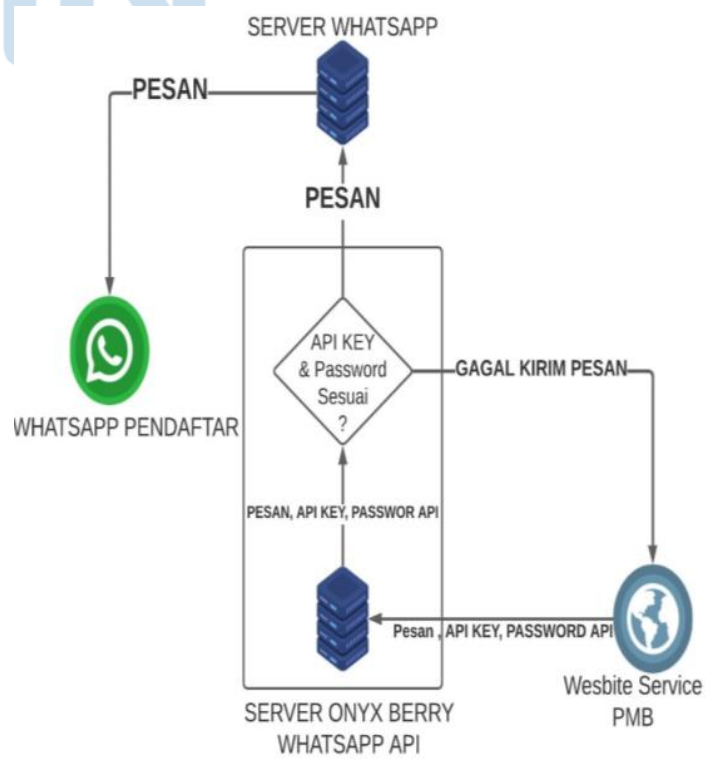

Gambar 4. Alur kerja API Whatsapp dalam sistem 
Gambar 4 diatas mejelaskan bahwa Website Service PMB akan mengirimkan Pesan, API Key, dan Password API ke Server Onyx Berry penyedia Whatsapp API. Kemudian akan dicek kesesuaian API Key dan Password untuk kemudian pesan diteruskan ke Server Whatsapp. Pesan yang sudah sampai di Server Whatsapp akan dikirimkan ke Whatsapp pendaftar. Tampilan Registrasi Mahasiswa dapat dilihat pada Gambar 5.

\begin{tabular}{l} 
PVIB - Universitos Viethodist Inoonesia \\
Registrasi Akun Calon Mahasiswa/i \\
Nama Lengkap \\
Jenis Kelamin \\
--Pilih-- \\
Tlp/Handphone \\
E-Mail \\
Password \\
Daftar \\
\hline
\end{tabular}

Gambar 5. Registrasi calon mahasiswa baru

Dashboard Admin untuk melihat data aktual pendaftar seperti jumlah pendaftar, jumlah akun, jumlah mahasiswa yang diterima dan jumlah pendaftar yang terkonfirmasi sudah membayar uang kuliah dan pendaftaran, dapat dilihat pada Gambar 6.

\section{Dashboard}

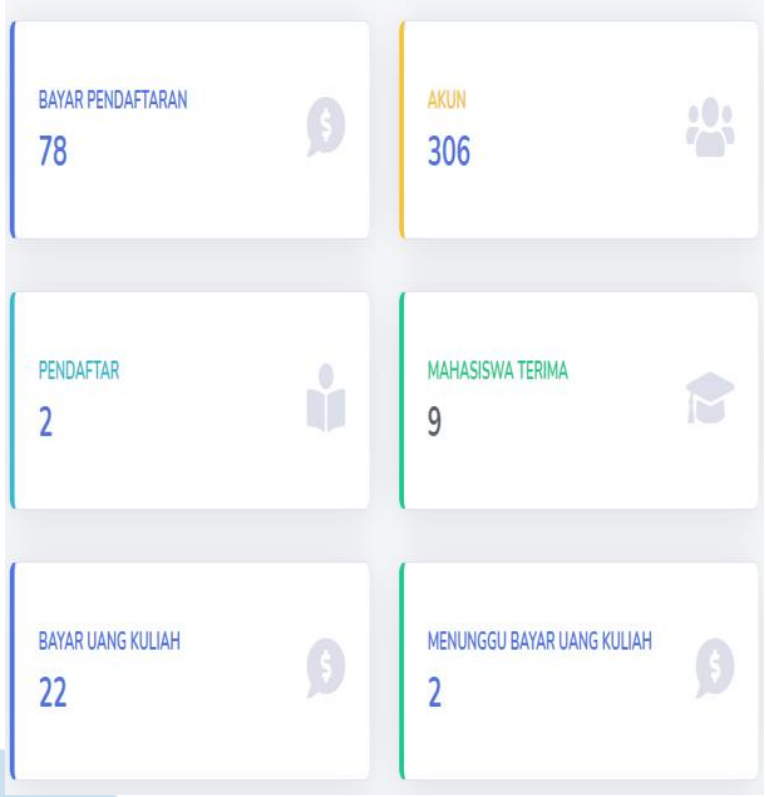

Gambar 6. Dashboard admin

Data Soal TPA diinput melalui sistem oleh admin, dapat dilihat pada Gambar 7.

\section{Data Soal TPA}

Show $10 \multimap$ entries

No $\uparrow \downarrow$ Kategori $\uparrow \downarrow$ Soal

\begin{tabular}{|lll|}
\hline 1 & $\begin{array}{l}\text { TES } \\
\text { PADANAN }\end{array}$ & Objektif \\
& & \\
\hline 2 & TES & Hulubalang \\
& PADANAN & \\
\hline 3 & TES & Remisi \\
& PADANAN & \\
\hline
\end{tabular}

Gambar 7. Data soal TPA 
Laporan Data Bayar Pendaftaran dapat di tampilkan pada Gambar 8.

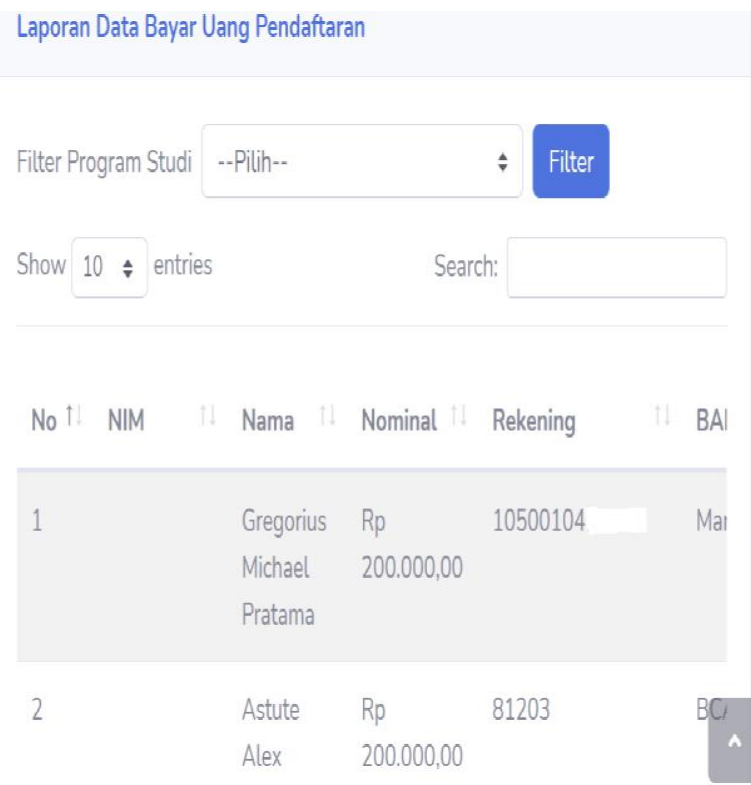

Gambar 8. Laporan data bayar pendaftaran

Laporan Data List Peserta TPA dapat di tampilkan pada Gambar 9.

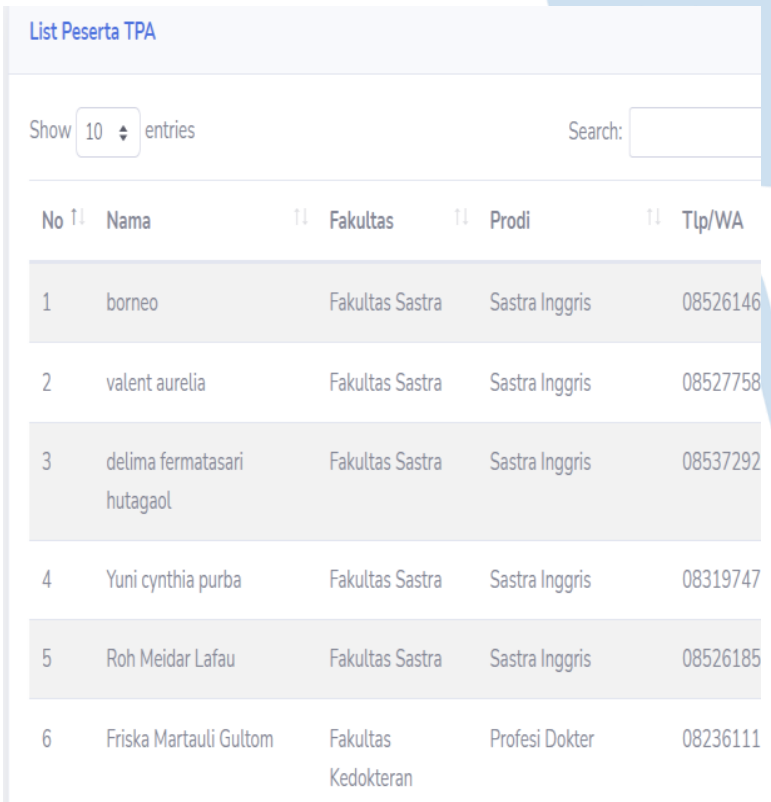

Gambar 9. List peserta TPA

\section{SIMPULAN}

Kesimpulan dari sistem yang dirancang adalah terpenuhinya kebutuhan untuk memberikan layanan yang baik kepada pendaftar melalui teknologi internet. Kemudahan untuk merekap data pendaftar, dan informasi alur pendaftaran hingga tahap pembayaran uang kuliah. Panitia pendaftaran juga dapat melihat laporan pendaftar yang daftar dilokasi/offline dan online. Secara keseluruhan, sistem ini sangat membantu untuk proses penerimaan mahasiswa baru.

\section{DAFTAR PUSTAKA}

[1] A. Permani and P. Priyanto, "Pengembangan Modul Elektronik Pemrograman Berorientasi Objek untuk Siswa Kelas XI Rekayasa Perangkat Lunak dengan Model Four-D," Elinvo (Electronics, Informatics, Vocat. Educ., vol. 4, no. 1, pp. 12-16, 2019, doi: 10.21831/elinvo.v4i1.28260.

[2] M. G. Priangga and M. S. Haq, "Peran Manajerial Kepala Sekolah Dalam Meningkatkan Profesionalisme Guru Di Era Revolusi Industri 4.0,' J. Inspirasi Manaj. Pendidik., vol. 9 , no. 2, pp. 460-474, 2021.

[3] S. F. Sihotang and R. Ramadhani, "Analisis Kemampuan Penggunaan Teknologi Informasi Mahasiswa Dalam Pembelajaran Matematika di Era Pandemi Covid-19," J. Ilm. Mat. dan Terap., vol. 18, no. 1, pp. 47-61, 2021.

[4] H. G. Simanullang and A. P. Silalahi, "Sistem Kuesioner Penilaian Kinerja Guru Menggunakan Metode Multifactor Evaluation Process (MFEP) Pada SMP Negeri 3 Binjai," $J$. Inform. Kaputama(JIK), vol. 4, no. 2, pp. 149-157, 2020.

[5] A. F. Sallaby and I. Kanedi, "Perancangan Sistem Informasi Jadwal Dokter Menggunakan Framework Codeigniter," pp. 48-53, 2020.

[6] M. A. Manuhutu and I. S. Rajagukguk, "Perancangan Sistem Informasi Orangtua / Wali Mahasiswa Berbasis Web Pada Universitas Victory Sorong," vol. 4, no. September, pp. 337 $350,2020$.

[7] F. Hanifah and A. Fatmawati, "Sistem Informasi Penerimaan Siswa Baru Madrasah Ibtidaiyah Program Khusus Kartasura," Emit. J. Tek. Elektro, vol. 20, no. 02, pp. 117-122, 2020.

[8] D. Suhartono, "System of Information Feedback on Archive Using Term Frequency- Inverse Document Frequency and Vector Space Model Methods," vol. 3, no. 1, pp. 36-42, 2020.

[9] A. Aziz, Hartono, A. Rohman, and D. Kusumoaji, "Sistem Dokumentasi Rancang Bangun Pesawat Udara Berbasis Web Menggunakan Framework CodeIgniter dan PostgreSQL dengan Metode Prototype," vol. 5, no. 3, 2020.

[10] R. Valarezo and T. Guarda, "Comparative analysis of the laravel and codeigniter frameworks: For the implementation of the management system of merit and opposition competitions in the State University Península de Santa Elena," Iber. Conf. Inf. Syst. Technol. Cist., vol. 2018-June, pp. 1-6, 2018, doi: 10.23919/CISTI.2018.8399242.

[11] D. Dermawan, D. S. D. Putra, and L. W. Kusuma, "Aplikasi Pendaftaran Seminar Menggunakan Metode Mvc Berbasis Website Menggunakan Framework Codeigniter 3.1.10," J. Algor, vol. 1, no. 2, pp. 23-29, 2020.

[12] M. Destiningrum and Q. J. Adrian, "Sistem Informasi Penjadwalan Dokter Berbassis Web Dengan Menggunakan Framework Codeigniter (Studi Kasus: Rumah Sakit Yukum Medical Centre),"J. Teknoinfo, vol. 11, no. 2, p. 30, 2017, doi: 10.33365/jti.v11i2.24

[13] R. W. T. Hartono, A. W. Fauziah, M. Y. Fadhlan, J. P. Tarigan, and K. Kunci, "Perancangan dan Implementasi Aplikasi IoT untuk Fitting Baju Virtual Menggunakan Pengolahan Citra Dengan Metoda Euclidean Distance," pp. 26-27, 2020.

[14] R. Sandyca Novenza and I. Gede Susrama Mas Diyasa, "Perancangan Sistem Uji Sertifikasi Kompetensi Berbasis GraphQL," J. Inform. dan Sist. Inf., vol. 1, no. 2, 2020.

[15] A. P. Wibowo, Sumiati, and D. S. D, "Rancangan Sistem Informasi E-Commerce Untuk Usaha Fashion Bountyclothing Pada Cv. Aldikarya Intisar," Juminten J. Manaj. Ind. dan Teknol., vol. 01, no. 04, pp. 24-36, 2020.

[16] Y. Wulandari and H. Sulistiani, "Rancang Bangun Aplikasi 
Presensi Sms Gateway Berbasis Web Dengan Framework Codeigniter Pada SMKN 1 TRIMURJO," vol. 1, no. 1, pp. 43-50, 2020.

[17] S. Aprilia, "Sistem Informasi Absensi Berbasis Website Menggunakan API WhatsApp dengan Metodologi Incremental (Studi Kasus: SMP Negeri 29 Pekanbaru)," J. Appl. Informatics Comput., vol. 4, no. 1, pp. 38-44, 2020, doi: 10.30871/jaic.v4i1.1966.
[18] A. P. Silalahi and H. G. Simanullang, "Multifactor Evaluation Process (MFEP) untuk Rekomendasi Jurusan pada Sekolah Menengah Atas," METHODA, vol. 8, no. 1, pp. 84-91, 2018.

[19] M. Amir Baihaqi, D. Aribowo, and M. A. Hamid, "Pengembangan Aplikasi Sistem Informasi Prakerin Berbasis Android di Jurusan Elektronika Industri SMKN 1 Cikande," J. Edukasi Elektro, vol. 4, no. 1, 2020. 